\title{
Ventilation and oxygen uptake by three species of Nereis (Annelida: Polychaeta). I. Effects of hypoxia
}

\author{
Erik Kristensen
}

Institute of Ecology and Genetics, and Department of Zoophysiology, University of Aarhus, DK-8000 Aarhus C, Denmark

\begin{abstract}
Oxygen consumption of Nereis virens, $N$. succinea and $N$. diversicolor were measured during gradually decreasing oxygen tensions. Two techniques were employed to determine the effect of muscular activity on oxygen consumption: (1) worms free in water, using respirometer; (2) worms in polyethylene tubes simulating natural conditions with additional measurements of ventilation, using a direct flow-sensing technique. For these polychaetes muscular movements of the entire body provided the basis for both motor and ventilatory activity. When free in water all 3 nereids showed conformity of oxygen consumption during lowered oxygen tension, exhibiting uncontrolled and variable motor activity. In tubes, the worms showed conformity at high oxygen tensions and variable degrees of regulation at intermediate tensions: $N$. succinea exhibited a wide range of regulation (30 to $140 \mathrm{~mm}$ $\mathrm{Hg}$ ); $N$. virens was a weak regulator (30 to $70 \mathrm{~mm} \mathrm{Hg}$ ) $N$. diversicolor revealed intermediate regulatory abilities (30 to $90 \mathrm{~mm} \mathrm{Hg}$ ). Oxygen regulation at intermediate tensions was due to compensatory responses of ventilation (behavioural regulation) and oxygen extraction (physiological regulation). A correlation appeared to exist between regulatory ability of the species and reducing capacity of preferred sediment types; thus a good regulator ( $N$. succinea) commonly is found living in muddy sediment of high organic content, whereas the weakest regulator ( $N$. virens) prefers sandy sediments of low organic content.
\end{abstract}

\section{INTRODUCTION}

Nereid polychaetes commonly live in large numbers in the intertidal zone of estuarine and brackish waters, normally in sediments of medium to high organic content (Muus, 1967). When buried in sediment, they depend on water pumped through the burrows for oxygen supply. Previous studies concerning ventilatory patterns in Nereis spp. have revealed that ventilatory activity is intermittent, interrupted by periods of rest (Wells and Dales, 1951; Scott et al., 1976; Kristensen, 1981b). Since oxygen penetrates to a depth of only a few mm below the surface of sediments (Revsbech et al., 1980), animals buried in the sediment commonly are exposed to very low oxygen tensions during periods of ventilatory rest. It is well known that nereids are able to switch from aerobic to anaerobic metabolism during periodic oxygen depletion (Beadle, 1961; Scott, 1976; Schöttler, 1978, 1979; Jørgensen and Kristensen, 1980).

The capacity of several marine invertebrate groups for partial regulation of oxygen consumption in water of reduced oxygen tension is well studied. Commonly, a distinction is made between oxygen regulators which maintain a steady oxygen uptake over a wide range of ambient oxygen tensions, and oxygen conformers in which the amount of oxygen consumed is directly dependent on oxygen availability (Prosser, 1973). However, this does not hold in general since perfect regulation or conformity is very rare. More often the rates correspond to intermediate regulatory patterns (Mangum and Van Winkle, 1973).

Several reports concerning the regulatory ability of polychaetes have revealed contradictory results. Among the polychaetes that have been tested, regulation of oxygen uptake was found in Nereis spp. (Dam, 1937; Lindroth, 1938; Theede, 1973; Theede et al., 1973), Ophelia bicornis (Beis et al., 1980), Lumbrineris zonata (May, 1972) and conformity of oxygen uptake in Nereis spp., Arenicola marina, Abarenicola assimilis, Glycera americana, Perineris nuntia (Shumway, 1979), Mesochaetopterus taylori (Petersen and Johansen, 1967), Abarenicola pacifica (May, 1972), and Cirriformia tentaculata (Dales and Warren, 1980). The measurements of oxygen uptake during such experiments may be affected by a variety of factors, such as previous 
environmental history, nutritional state, size, and state of activity (Beis et al., 1980). In this paper a distinction is made between motor and ventilatory activity; muscular movements of the entire body of these polychaetes provide the basis for both forms of activity and will, as such, affect oxygen uptake.

The aim of the present work was to investigate responses of simultaneously measured ventilation and oxygen consumption in the polychaetes Nereis virens Sars, $N$. succinea (Frey \& Leuckart) and $N$. diversicolor O. F. Müller in conditions of reduced oxygen. Earlier measurements on oxygen consumption of Nereis during hypoxia were made without consideration of ventilatory activity (Theede, 1973; Shumway, 1979). By using artificial tubes simulating the worms' natural burrows and by monitoring ventilatory activity, it was hoped that a better understanding of polychaete respiratory responses to hypoxia could be achieved.

\section{MATERIALS AND METHODS}

\section{Animals}

Nereis virens, $N$. succinea and $N$. diversicolor were collected during March and April, 1982 in the estuary, Kysing Fjord, close to Aarhus, Denmark (Muus, 1967). $N$. virens was collected on a sandflat of medium to low organic content; $N$. succinea, in sandy mud with dense growth of Mytilus edulis; $N$. diversicolor, in silty sand. Habitat temperature was 6 to $10^{\circ} \mathrm{C}_{i}$ mean salinity, ca. $20 \%$ S. The collection area was subjected to variable periods of submergence. Only intact worms were used for experiments.

The worms were acclimated to experimental conditions, $16^{\circ} \mathrm{C}$ and $20 \% \mathrm{~S}$, for at least $7 \mathrm{~d}$ in a recirculating seawater aquarium partially filled with natural sediment. Two d prior to use, the worms were placed in polyethylene tubes of appropriate sizes, and stored in petri dishes to void their guts.

\section{Ventilation measurements}

Experiments were performed in a 121 darkened aquarium thermostatted at $16^{\circ} \mathrm{C}$. The tubes containing the worms were placed in V-shaped Plexiglas tubes, simulating the natural position of the worms in the sediment (Fig. 1).

Ventilation was determined with an electromagnetic flowmeter (Micron Instr. Corp.) and continuously recorded by a Hewlett-Packard 7132A recorder (Kristensen, 1981b).

Ventilation amplitude was measured as average water flow computed as mean flow rate during periods

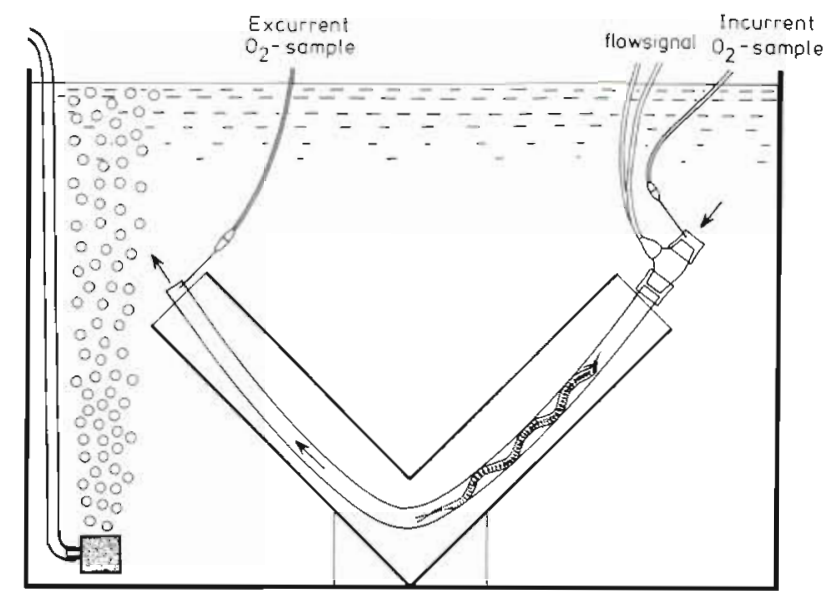

Fig. 1. Experimental set-up for measuring Nereis ventilation and oxygen uptake. Cables for flow signal are connected to an electromagnetic flowmeter. Tubes for $\mathrm{O}_{2}$-samples are connected to a Radiometer $\mathrm{P}_{\mathrm{O}_{2}}$-electrode

of active ventilation $\left(\dot{V}_{\mathrm{w}}\right)$. Measurements for each individual were carried out over $1 \mathrm{~h}$ intervals. During ventilation periods the water flow was integrated and averaged. Ventilation was expressed as $\mathrm{ml} \mathrm{min}^{-1}$, standardized to a $0.5 \mathrm{~g}$ wet wt. individual of each species, according to the weight relationship reported by Kristensen (1981b). Ventilation activity was determined both as ventilation amplitude $\left(\dot{V}_{w}\right)$ and as average duration of ventilation periods, determined as percent of total measured time $\left(D_{v}\right)$.

\section{Measurements of oxygen uptake}

\section{During active ventilation}

Oxygen uptake during active ventilation was determined by measuring the water flow as described; simultaneously, inspiratory and expiratory water samples were taken from the tube for oxygen analysis with Radiometer $\mathrm{P}_{\mathrm{O}_{2}}$-electrodes (Kristensen, 1981b). Incurrent and excurrent water samples from the tube passed the $\mathrm{P}_{\mathrm{O}_{2}}$-electrodes at a constant rate (ca. $1 \mathrm{ml} \mathrm{min}^{-1}$ ). Oxygen extraction was recorded continuously (Fig. 2). For each species 4 to 6 individuals were used (weight range: $N$. virens, 0.8 to $1.5 \mathrm{~g}$; $N$. succinea, 0.4 to $0.9 \mathrm{~g}$; $N$. diversicolor, 0.2 to $0.5 \mathrm{~g}$ wet wt.). $\mathrm{P}_{\mathrm{O}_{2}}$ was reduced in steps of ca. $20 \mathrm{~mm} \mathrm{Hg}$, from 155 to $10 \mathrm{~mm} \mathrm{Hg}$ by bubbling nitrogen through the water. Ventilation and oxygen extraction were recorded immediately after each step for ca. $1 \mathrm{~h}$ for each individual.

Oxygen consumption $\left(\dot{\mathrm{V}}_{\mathrm{O}_{2}}\right)$ was calculated as:

$$
\dot{\mathrm{V}}_{\mathrm{O}_{2}}=\left(\mathrm{C}_{\mathrm{O}_{2}}-\mathrm{C}_{\mathrm{eO}_{2}}\right) \cdot \dot{\mathrm{V}}_{\mathrm{w}}
$$

where $\mathrm{C}_{\mathrm{iO}_{2}}$ and $\mathrm{C}_{\mathrm{eO}}$ = incurrent and excurrent oxygen 
concentrations. $\dot{\mathrm{V}}_{\mathrm{O}_{2}}$ was expressed as $\mu \mathrm{g} \mathrm{O}_{2} \mathrm{~g}^{-1} \mathrm{~h}^{-1}$ standardized to a $0.5 \mathrm{~g}$ wet wt. individual, according to Kristensen (1981b). A $2.5 \mathrm{~g} \mathrm{~N}$. virens that showed great variations in $\dot{V}_{w}$ was used to determine the relationship between $\dot{V}_{w}$ and $\dot{V}_{\mathrm{O}_{2}}$ (or oxygen extraction).

\section{Worms free in water}

Oxygen uptake determinations of worms removed from the tubes were performed in a closed $27 \mathrm{ml}$ respirometer thermostatted at $16^{\circ} \mathrm{C}$. Oxygen tension was measured by a Radiometer $\mathrm{P}_{\mathrm{O}_{2}}$-electrode. $\mathrm{A}$ magnetic stirrer assured sufficient mixing of the medium. In experiments change of $P_{\mathrm{O}_{2}}$ was recorded continuously. The worms were allowed to reduce $P_{\mathrm{O}_{2}}$ from 155 to $20 \mathrm{~mm} \mathrm{Hg}$. Four individuals of each species were used, and $\dot{\mathrm{V}}_{\mathrm{O}_{2}}$ was standardized to a $0.5 \mathrm{~g}$ wet wt. individual for comparison.

\section{Role of microbial oxygen uptake}

When a nereid inhabits a clean polyethylene tube, it will quickly line the inner surface of the tube with mucus. This mucus may serve as a rich substrate for microbial growth (Aller and Yingst, 1978).

To test possible interference of microbial oxygen uptake on measurements of Nereis oxygen uptake, a tube $(20 \mathrm{~cm}$ long, $0.5 \mathrm{~cm}$ diameter) was used that had previously been occupied by 1 Nereis virens for $4 \mathrm{~d}$. Gradually increasing water flow $\left(1.4\right.$ to $8.0 \mathrm{ml} \mathrm{min}^{-1}$ ) was produced through the tube by a peristaltic pump. Water flow and microbial oxygen extraction were measured as described earlier. The tube was then cleaned by a pipecleaner and washed in warm water $\left(60^{\circ} \mathrm{C}\right)$, and the procedure was repeated.

\section{RESULTS}

\section{Effects of reduced oxygen tension on ventilation}

Ventilation in the 3 species of Nereis was intermittent, with alternations between periods of rest and bursts of ventilatory activity (Fig. 2), in agreement with reports of Wells and Dales (1951), Scott et al. (1976) and Kristensen (1981b).

As $\mathrm{P}_{\mathrm{O}_{2}}$ declined, average duration of bursts of ventilation $\left(D_{v}\right)$ increased for all 3 species (Fig. $3 A$ ). $D_{v}$ for Nereis virens and $N$. diversicolor showed an increase of about $40 \%$ as $\mathrm{P}_{\mathrm{O}_{2}}$ was reduced from air saturation down to 10 to $30 \mathrm{~mm} \mathrm{Hg}$. These 2 species appeared very much alike regarding $D_{v}$, and at air saturation $D_{v}$ was ca. $60 \%$ for both. N. succinea, in contrast, showed

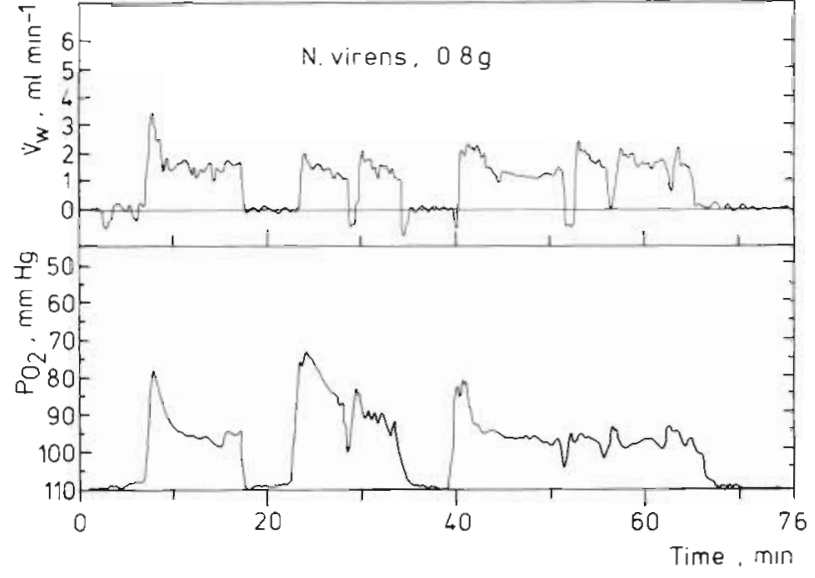

Fig. 2. Nereis virens. Ventilation and excurrent oxygen tension of a $0.8 \mathrm{~g}$ individual. Duration of recording $76 \mathrm{~min}$. Incurrent $\mathrm{P}_{\mathrm{O}_{2}}=110 \mathrm{~mm} \mathrm{Hg}$

a constant $D_{v}$ of $25 \%$ down to about $100 \mathrm{~mm} \mathrm{Hg}$, followed by an increase at lower tensions $(\mathrm{p}<0.05)$. At $10 \mathrm{~mm} \mathrm{Hg}, \mathrm{D}_{v}$ for this species reached the same level as the other $2(-80 \%)$.

Ventilation amplitude $\left(\dot{V}_{\mathrm{w}}\right)$ appeared almost constant for all 3 species at $\mathrm{P}_{\mathrm{O}_{2}}$ below $100 \mathrm{~mm} \mathrm{Hg}$ (Fig. $3 \mathrm{~B}) . \dot{V}_{\mathrm{w}}$ for Nereis virens and $N$. diversicolor showed the same pattern, except that $\dot{V}_{w}$ for the latter was about twice that of the former $(p<0.05)$. Both species showed a decrease of about $40 \%(\mathrm{p}<0.05)$ when $\mathrm{P}_{\mathrm{O}_{2}}$ decreased to about 100 to $110 \mathrm{~mm} \mathrm{Hg}$. At lower tensions $\dot{V}_{w}$ was fairly constant. In contrast, $\dot{V}_{w}$ for $N$. succinea was nearly constant over the whole range of $\mathrm{P}_{\mathrm{O}_{2}}$ at a level noticeably higher than $N$. diversicolor and about 2 to $2 \frac{1 / 2}{2}$ times higher than $N$. virens $(\mathrm{p}<0.05)$.

The 3 species of Nereis showed much the same pattern for the total volume of water passing the tubes per unit time $\left(\dot{\mathrm{V}}_{\mathrm{w}} \times \mathrm{D}_{\mathrm{v}}\right)$ : a decrease to a minimum at 80 to $100 \mathrm{~mm} \mathrm{Hg}$ was followed by an increase at lower tensions (Fig. $3 \mathrm{C}$ ). On the other hand the volume of water and the magnitude of the changes was quite different. $N$. virens and $N$. succinea ventilated nearly identical volumes down to $100 \mathrm{~mm} \mathrm{Hg}$, but at lower tensions the latter showed a more rapid increase than the former. $N$. succinea eventually reached the level of $N$. diversicolor at $30 \mathrm{~mm} \mathrm{Hg}$, where these 2 species ventilated at a rate approximately 2 times that of $N$. virens.

\section{Effects of reduced tension on oxygen uptake}

Worms free in water

When Nereis spp. were removed from the tubes, $\dot{V}_{\mathrm{O}_{2}}$ appeared highly dependent on external $\mathrm{P}_{\mathrm{O}_{2}}$ over the 


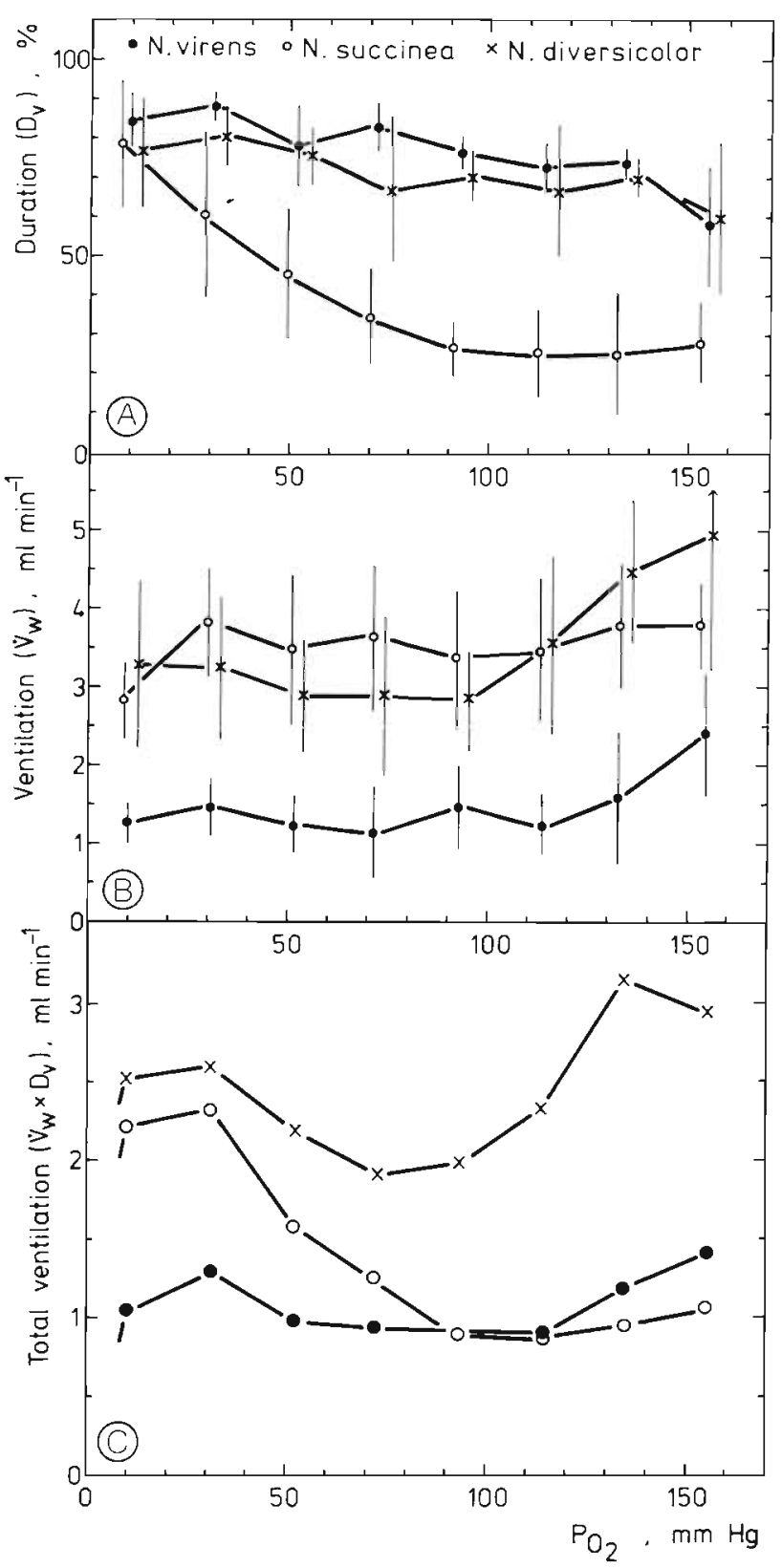

Fig. 3. Nereis virens, $N$. succinea, $N$. diversicolor. (A) Duration of ventilation (\% of total measured time $\left[D_{\mathrm{v}}\right]$ ) during decreasing oxygen tension $\left(\mathrm{P}_{\mathrm{O}_{2}}\right)$. (B) Ventilation amplitude $\left(\nabla_{w}\right)$ during decreasing oxygen tension $\left(\mathrm{P}_{\mathrm{O}_{2}}\right)$ for $0.5 \mathrm{~g}$ wet wt. standard individuals. (C) Total volume of water ventilated per unit time $\left(\vec{V}_{w} \times D_{v}\right)$ for standard individuals. Results in (A) and (B) given as mean $\pm \mathrm{S}$. D. for ca. $1 \mathrm{~h}$ recordings of 4 to 6 individuals

range from 155 to $20 \mathrm{~mm} \mathrm{Hg}$ (Fig. 4). The values for the 3 species did not differ over the major part of the $\mathrm{P}_{\mathrm{O}_{2}}$ range studied. The rates presented here for tubeless worms seem higher than earlier reported resting rates (Kristensen, 1981b). This agrees with direct observations during the experiments. The worms exhibited a relatively high level of motor activity; possibly they

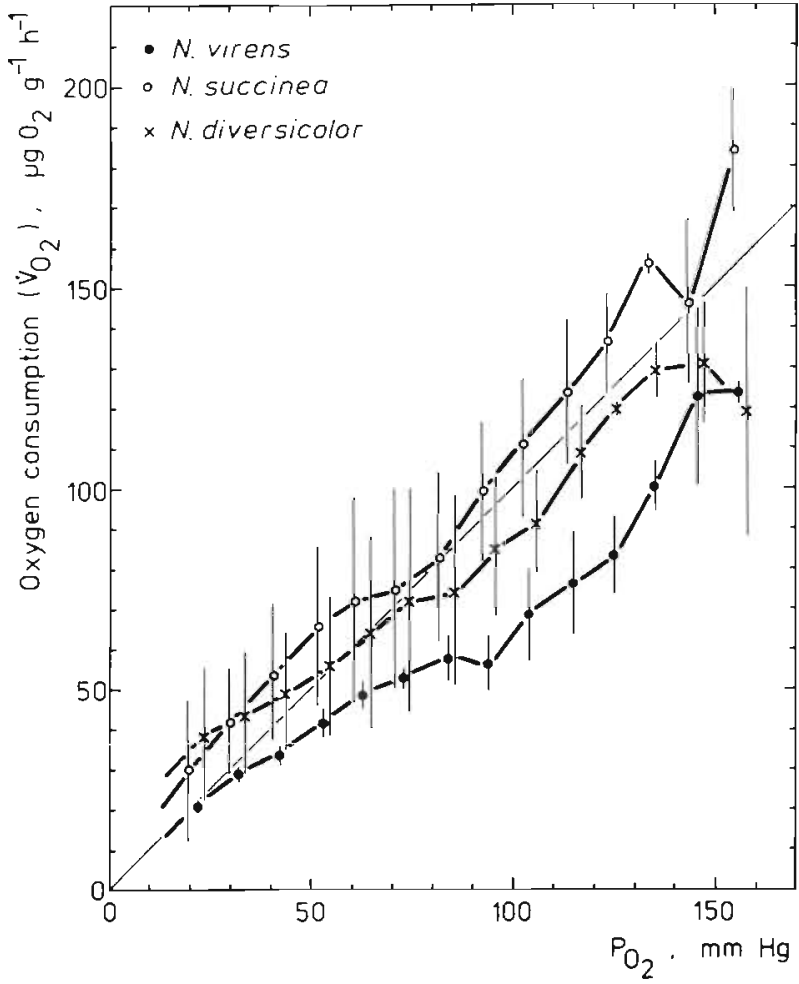

Fig. 4. Nereis virens, $N$. succinea, $N$. diversicolor. Oxygen consumption by $0.5 \mathrm{~g}$ wet wt. standard individuals, free in water, during declining oxygen tension. Results given as mean \pm S.D. for 4 individuals as indicated by error bars

were disturbed by the magnetic stirrer or activity was related to searching for a suitable place to construct a burrow.

\section{Active worms in tubes}

Each ventilation burst started with a peak of both ventilation amplitude and oxygen extraction (Fig. 2). Nereids cornmonly start a burst of ventilatory activity with a peak of $\dot{V}_{w}$, followed by a more or less constant amplitude. This ventilation peak caused a fast renewal of tube water, presumably a mechanism for rapid removal of metabolic wastes and oxygen deficient water. The observed peak in oxygen extraction was a consequence of the previous resting period, where the worm had more or less exhausted the oxygen available in the tube. As for $\dot{V}_{w}$, the peak of oxygen extraction was followed by a period of constant extraction. $\dot{V}_{\mathrm{O}_{2}}$ was computed from these constant periods.

The percentage extraction of oxygen removed from water passing through the gills during declining $\mathrm{P}_{\mathrm{O}_{2}}$ often reflects the ability of marine invertebrates to regulate $\dot{\mathrm{V}}_{\mathrm{O}_{2}}$ (Bayne, 1971). In water fully saturated with oxygen, extraction was rather low; there was a significant difference $(\mathrm{p}<0.05)$ between Nereis diversicolor $(5.5 \%)$ and the other 2 Nereis spp. (11 to $12 \%$ ) 
(Fig. 5). During a decline in $\mathrm{P}_{\mathrm{O}_{2}}$ below $100 \mathrm{~mm} \mathrm{Hg}$, oxygen extraction showed a rapid increase, reaching $27 \%$ for $N$. diversicolor and $35 \%$ for $N$. virens and $N$. succined at $10 \mathrm{~mm} \mathrm{Hg}$. This suggests that Nereis spp. physiologically regulate oxygen uptake to some extent at low tensions.

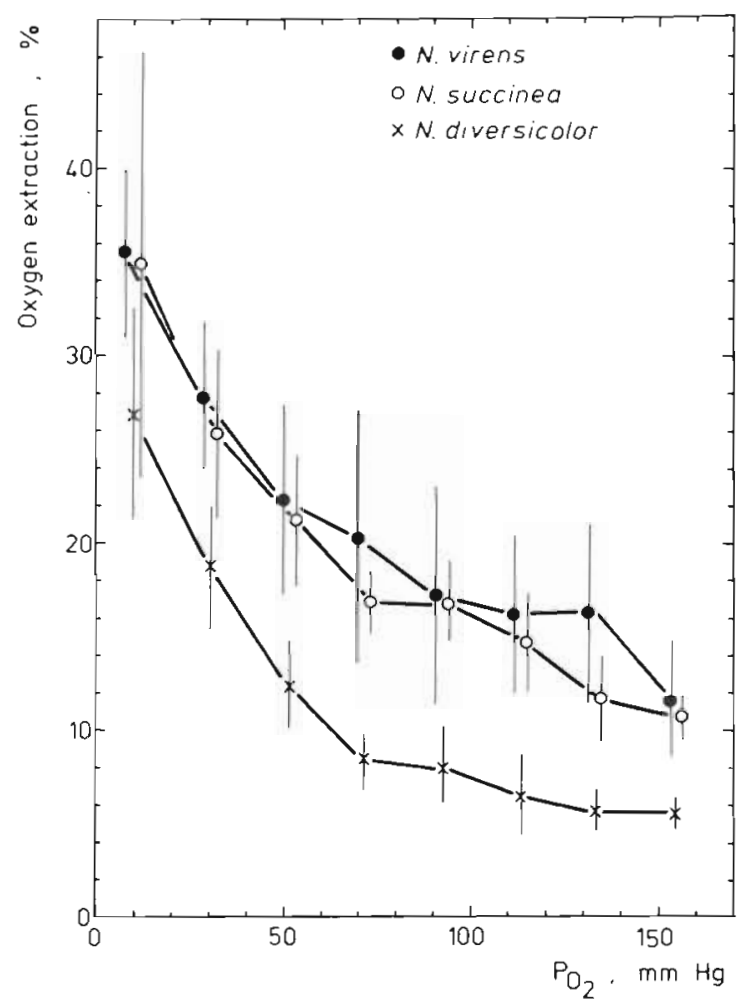

Fig. 5. Nereis virens, N. succinea, $N$. diversicolor. Fractional extraction of oxygen from water passing the tube during decreasing oxygen tension. Results given as mean $\pm S$.D. for ca. $1 \mathrm{~h}$ recordings of 4 to 6 individuals

Oxygen consumption rates during periods of active ventilation were clearly influenced by ventilatory activity. For the $2.5 \mathrm{~g} \mathrm{~N}$. virens tested, a first-order relationship $\left(\dot{V}_{\mathrm{O}_{2}}=\mathrm{b}+\mathrm{a} \times \dot{\mathrm{V}}_{\mathrm{w}}\right)$ was evident between ventilation activity expressed as ventilation amplitude $\left(\dot{\mathrm{V}}_{\mathrm{w}}\right)$ and oxygen consumption $\left(\dot{\mathrm{V}}_{\mathrm{O}_{2}}\right)$ (Fig. 6). Similar relationships have been shown for other marine invertebrates (Halcrow and Boyd, 1967; Hamwi and Haskin, 1969; Thompson and Bayne, 1972; Newell and Kofoed, 1977). A decrease in $\dot{V}_{w}$ during declining $P_{\mathrm{O}_{2}}$ would then produce changes in measured $\dot{V}_{\mathrm{O}_{2}}$, which is not directly an effect of hypoxial conditions.

During active ventilation periods, $\dot{\mathrm{V}}_{\mathrm{O}_{2}}$ was clearly influenced by external $\mathrm{P}_{\mathrm{O}_{2}}$ (Fig. 7). For Nereis virens and $N$. diversicolor a high degree of dependence on $\mathrm{P}_{\mathrm{O}_{2}}$ was found. $\dot{\mathrm{V}}_{\mathrm{O}_{2}}$ for these species did not differ significantly $(\mathrm{p}>0.10)$. $N$. succinea, in contrast, showed moderate independence during active ventilation periods, reaching uptake rates twice those for the

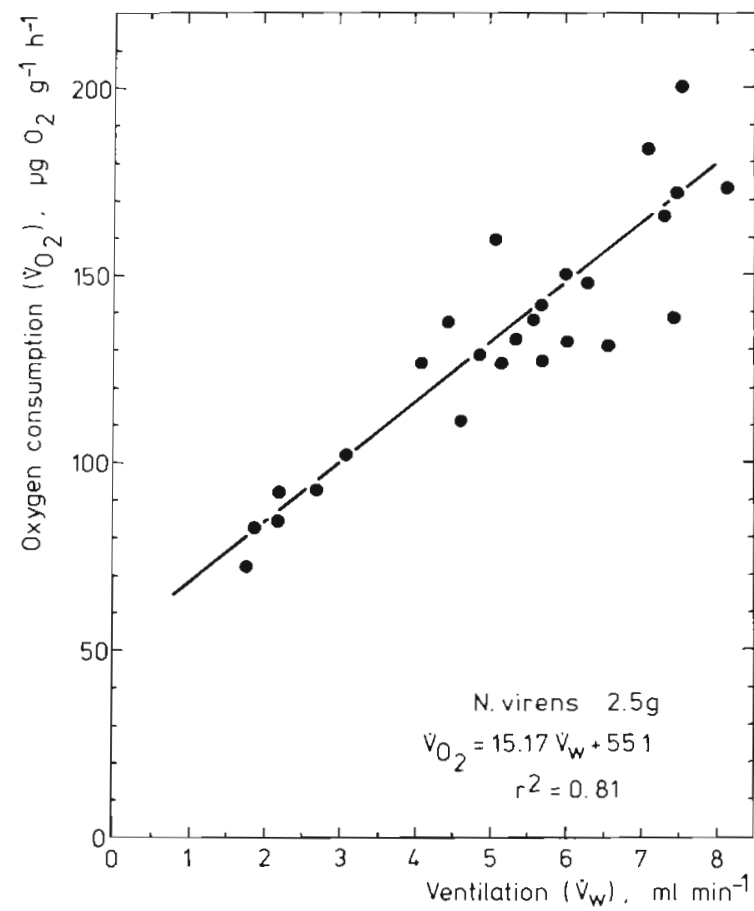

Fig. 6. Nereis virens. Oxygen consumption $\left(\dot{V}_{\mathrm{O}_{2}}\right)$ by 1 individual plotted against ventilation amplitude $\left(\vec{V}_{w}\right)$. Line fitted by equation: $\dot{V}_{O_{2}}=a \cdot \dot{V}_{w}+b$

other 2 species at all $P_{\mathrm{O}_{2}}$ 's $(p<0.01)$ (Fig. 7). By considering the duration of bursts of ventilation $\left(D_{v}\right.$ ) (Fig. $3 \mathrm{~A})$, the amount of oxygen consumed per unit time was very similar at intermediate oxygen tensions for the 3 species (Fig, 8). Corrected for $D_{v}$, the curves for the 3 species are more or less S-shaped; dependent uptake at high oxygen tensions, independence at intermediate, and dependent uptake at low tensions. The weakest regulator, $N$. virens, showed dependence down to about $70 \mathrm{~mm} \mathrm{Hg}$, followed by independence to $30 \mathrm{~mm}$ $\mathrm{Hg}$; for $N$. diversicolor, independence occurred in the range 30 to $90 \mathrm{~mm} \mathrm{Hg}$; the strongest regulator, $N$. succinea, was independent of ambient $\mathrm{P}_{\mathrm{O}_{2}}$ in the range 30 to $140 \mathrm{~mm} \mathrm{Hg}$.

\section{Microbial oxygen uptake}

It proved important to clean the polyethylene tubes before measurements of Nereis oxygen uptake. The mucus-lined tube showed considerable oxygen uptake (Fig. 9A) of the same order of magnitude as that for the worm itself. Changes in water current through the tube produced only slight changes in the measured microbial oxygen uptake. This background microbial uptake could be a serious source of error in experiments of this kind if no cleaning procedure was employed. The cleaning procedure used proved to be sufficient, since 


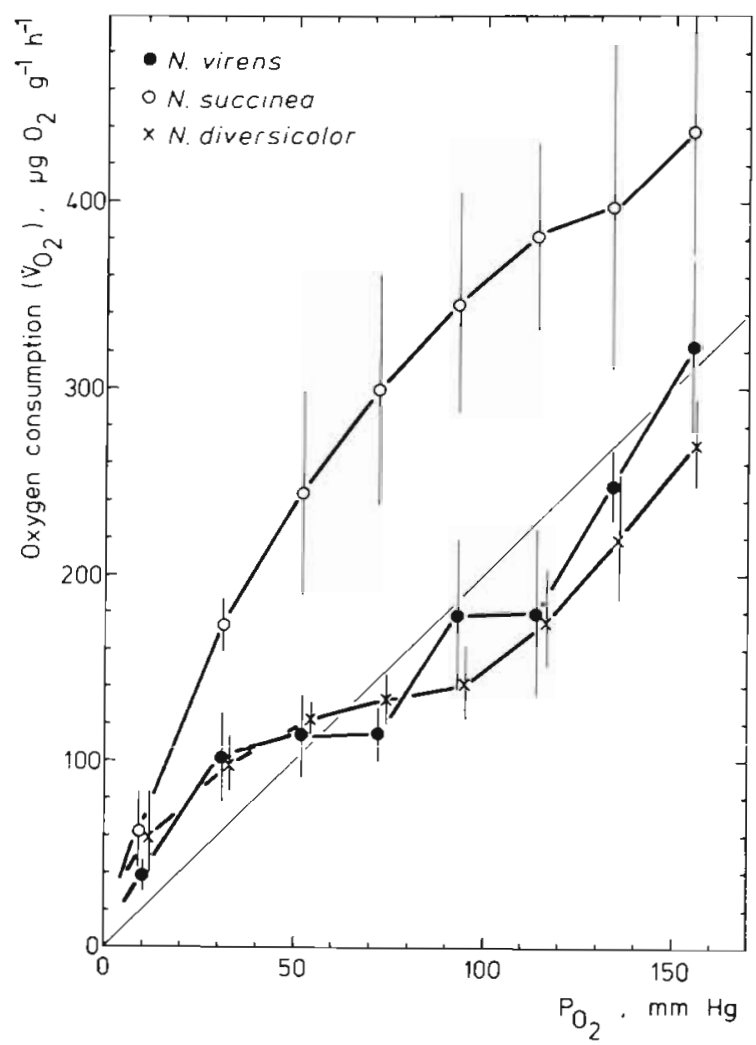

Fig. 7. Nereis virens, $N$. succinea, $N$. diversicolor. Oxygen consumption during active ventilation periods at declining oxygen tension; $0.5 \mathrm{~g}$ wet $\mathrm{wt}$. standard individuals. Results given as mean $\pm S$.D. for ca. $1 \mathrm{~h}$ recordings of 4 to 6 individuals

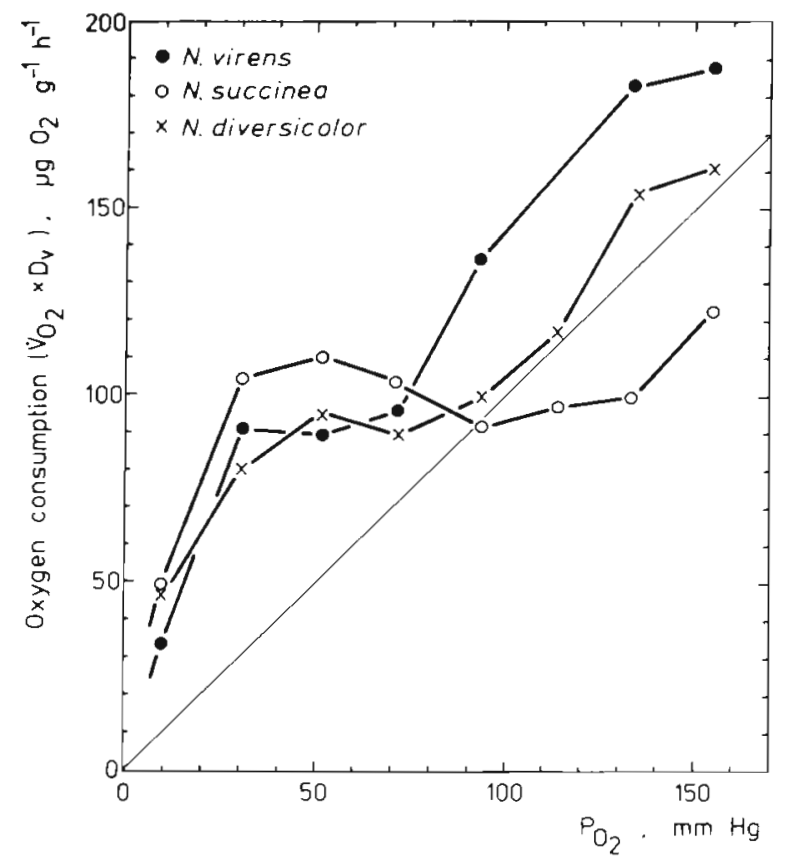

Fig. 8. Nereis virens, $N$. succined and $N$. diversicolor. Oxygen consumption by $0.5 \mathrm{~g}$ wet wt. standard individuals, integrated over total measured time $\left(\mathrm{D}_{v} \times \dot{\mathrm{V}}_{\mathrm{O}_{2}}\right)$ at each oxygen tension from 155 to $10 \mathrm{~mm} \mathrm{Hg}$

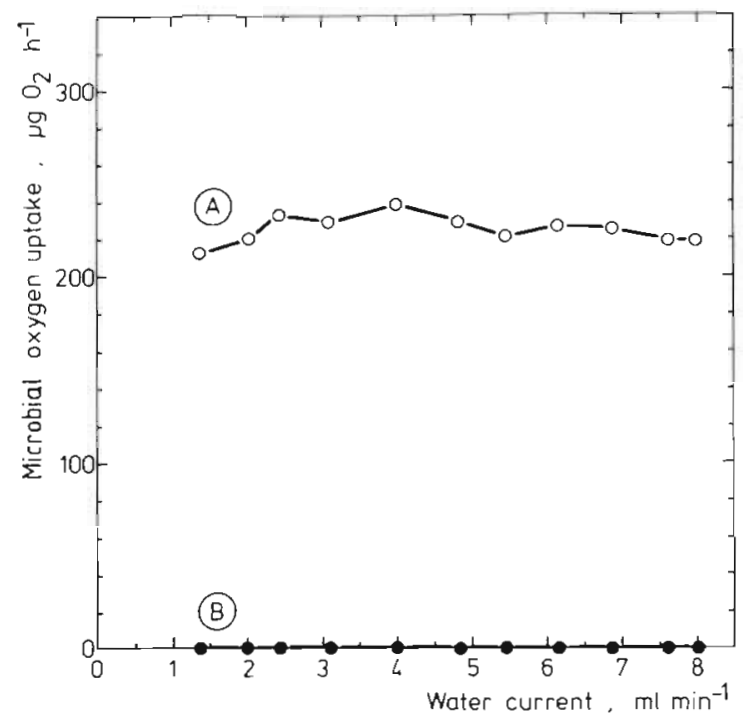

Fig. 9. Mictobiai oxygen consumption in empty polyethylene tubes, plotted against water current passing the tube. (A) Polyethylene tube occupied for $4 \mathrm{~d}$ by 1 Nereis virens before measurements. (B) Same tube cleaned by pipecleaner and washed in warm water

no measureable microbial oxygen uptake was observed after the treatment (Fig. 9B).

\section{DISCUSSION}

Investigations of oxygen consumption with declining tension in several marine invertebrates have indicated that oxygen uptake is regulated behaviourally by increasing ventilation as in Mytilus perna (Bayne, 1967) and Hyalinoecia tubicola (Dales et al., 1970), or regulated physiologically by maintaining a constant ventilation and increasing the fractional extraction of oxygen from the ventilatory current as in $M$. edulis (Bayne, 1971). Nereis spp. appeared capable of regulating oxygen uptake by combining both mechanisms. During a decline in oxygen tension, oxygen extraction increased markedly for the three species (Fig. 5); simultaneously, ventilation volume remained constant or decreased at tensions from 155 to $100 \mathrm{~mm}$ $\mathrm{Hg}$ (Fig. 3C). At lower tensions $\left(\mathrm{P}_{\mathrm{O}_{2}}<80\right.$ to $100 \mathrm{~mm}$ $\mathrm{Hg}$ ) ventilation periods were longer thereby increasing the volume of water pumped, although $\dot{V}_{w}$ was fairly constant (Fig. 3).

Under well-oxygenated conditions, oxygen extraction in the 3 nereid polychaetes was 6 to $12 \%$ which is considerable lower than reported for these species earlier: Nereis virens, 20 to $75 \%$ (Dam, 1937; Lindroth, 1938), 20\% (Mangum and Burnett, 1975). Other polychaetes, especially sedentary species with well developed gills - like Thelepus crispus, Eupolymnia heterobranchia, Neoamphitrite robusta (Dales, 1961) 
and Amphitrite ornata (Mangum and Burnett, 1975) are reported to extract 40 to $60 \%$. The generally lower rate of extraction found in the non-sedentary species such as Nereis might be explained by the possession of respiratory organs with smaller surface areas. Some annelids, including nereids, lack special respiratory organs but have localized structures, i.e. parapodia, which increase the surface area of the animals. The dorsal lamellae of Nereis parapodia are believed to be a major site of gas exchange, since these organs are highly vascularized (Mangum et al., 1980). The segmented 'gills' (parapodia) of Nereis spp. undoubtedly represent the more primitive condition. $N$. diversicolor extracts only about $5.5 \%$ of the available oxygen at high tensions, while $N$. virens and $N$. succinea extract 11 to $12 \%$. This difference can be explained by the size of the parapodia (Fig. 10). The dorsal parapodia

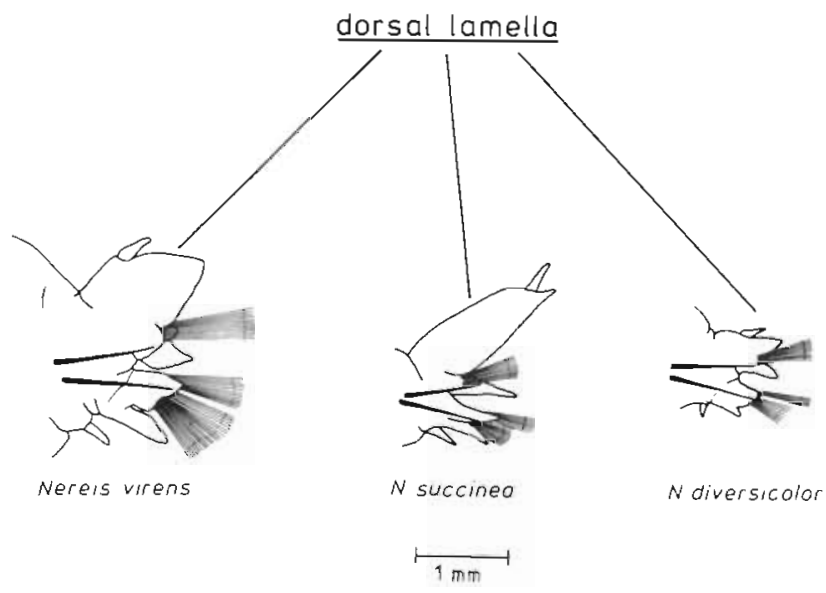

Fig. 10. Nereis spp. Parapodia from posterior third of body showing the dorsal lamella

lamellae of the posterior segments of both $N$. virens and $N$, succinea are large and leaf-shaped, while $N$. diversicolor has very small lamellae.

Experiments with tubeless worms suggest conformity of oxygen consumption (Fig. 4) in agreement with Shumway (1979) in $N$. virens and $N$. diversicolor. However, Theede (1973) and Theede et al. (1973) suggested a high degree of regulation for $N$. diversicolor and $N$. pelagica down to 30 to $40 \mathrm{~mm} \mathrm{Hg}$. Commonly, such experiments are performed with the worms free (i.e. tubeless) in the respirometer chamber. Results of such investigation may be misleading: it is impossible in those tests to determine the level of motor activity, which is known to have a substantial influence on oxygen uptake (Fig. 8; Dales, 1961; Newell and Northcroft, 1967; Mangum and Sassaman, 1969; Kristensen, $1981 \mathrm{~b})$. In the present investigation, rates of oxygen uptake for worms free in water greatly exceeded the rates reported by Shumway (1979), Cammen (1980), and Kristensen (1981b) for resting individuals. This suggests that when free in the water, worms may demonstrate an uncontrolled and high motor activity, which should be considered in such experiments. Moreover, respiratory independence can be modified by body size, temperature and physiological conditions (Bayne, 1971).

In tubes, Nereis spp. showed conformity ( $N$. virens and $N$. diversicolor) or moderate regulation ( $N$. succinea) during active ventilation periods (Fig. 7). Active oxygen uptake exceeded the uptake of tubeless worms by more than $100 \%$. A totally different picture emerged when oxygen uptake during ventilation was integrated over the total measured time (i.e. corrected for duration of ventilation, $D_{v}$ ) (Fig. 8). This resulted in conformity at high tensions and a good regulatory ability at intermediate tensions; $N$. succinea was the best regulator and $N$. virens the poorest, indicating a compensatory ventilation response, as reported for Cancer pagurus (Bradford and Taylor, 1982). Mangum and Burnett (1975) reported that during a reduction in environmental oxygen level the terebellid polychaete Amphitrite ornata showed only slight increases in ventilation. This response, in contrast to Nereis spp., was achieved by an increase in the amplitude of muscular movements rather than a change in parameters of the spontaneous rhythm itself. Mangum and Burnett concluded that there was no mechanism that increased the ventilation at low oxygen levels in Amphitrite. This is in agreement with Nereis only at oxygen levels above $50 \%$. The form of the curves in Fig. 8 at high oxygen tensions might be a consequence of a decrease in $\dot{V}_{w}$ during a lowering from air saturation to about $100 \mathrm{~mm}$ $\mathrm{Hg}$ (Fig. 3B). Such a decrease (especially for $N$. virens and $N$. diversicolor) will affect oxygen consumption as depicted in Fig. 6. At high tensions the worms possibly need no regulation since the blood with a half-saturation tension of $4.0 \mathrm{~mm} \mathrm{Hg}$ at $15^{\circ} \mathrm{C}$ (Weber, 1978) is likely to become fully oxygenated at these tensions. However, at lower tensions regulation becomes necessary. The oxygen uptake during active periods, corrected for $D_{v}$, showed a critical tension $P_{c}$ at about 30 to $40 \mathrm{~mm} \mathrm{Hg}$ for all 3 species (Fig. 8), below which the uptake rate decreased rapidly and ventilation tended to decrease (Fig. 3C).

Scott (1976) has shown that, during ventilatory rest periods, Nereis virens respires anaerobically, accumulating small amounts of lactic acid. Later, during ventilation periods, the oxygen debt is repaid. This might explain the high oxygen uptake of $N$. succinea during active ventilation periods compared to the other 2 species (Fig. 7). In $N$. succinea, ventilation pauses generally are longer than in the other species, generating a greater oxygen debt. Accordingly, and because of a shorter duration of ventilation periods, N. succinea 
consequently must exhibit a higher rate of oxygen uptake.

Hyman (1932) demonstrated that Nereis virens, when free in water, showed conformity of oxygen uptake; this agrees with the majority of reported cases. But she found that when in tubes, $N$. virens was predominantly an oxy-regulator, consuming $40 \%$ less oxygen at air saturation than when free in water. Both of Hyman's experiments were performed in respirometers, which would not permit the measurement of level of muscular activity (neither motor nor ventilatory activity) of the worms. The results of Hyman are supported by the present study even though the interpretation is somewhat different. She believed that when natural conditions were simulated by enclosing the worms in tubes, some internal mechanism made oxygen regulation possible. When free in water a number of unknown factors other than muscular activity could be responsible for the loss of the regulatory ability. The present study reveals that increased regulation within tubes is achieved partly by a compensatory response of ventilation (behavioural regulation) and partly by increased oxygen extraction (physiological regulation) at low tensions, whereas the missing ventilatory current is believed responsible for the apparent loss of regulatory ability when the worms are free in water.

It is tempting to assume that regulation reflected in an independent type of respiration is an adaptation necessary for life at low oxygen levels. However, the facts do not generally support such an assumption, since several tube-living intertidal polychaetes have been shown to be oxy-conformers, e.g. Mesochaetopterus taylori (Petersen and Johansen, 1967), Glycera dibranchiata (Mangum, 1970), Arenicola marina, Abarenicola assimilis, Glycera americana and Perineris nuntia (Shumway, 1979). The findings for the 3 species of Nereis tested here, on the other hand, suggest a correlation between regulatory ability and preferred sediment type. $N$. succinea, which showed the best regulatory ability, has a preferance for mud flats among lumps of Mytilus edulis (Rasmussen, 1973; Kristensen, 1981a). Conditions in such sediment types are highly reducing and low oxygen might be normal in the burrows of $N$. succinea. $N$. virens, showing the least regulatory ability, prefers sandy substrate of low organic content and is never found in pure mud flats (Rasmussen, 1973; Kristensen, 1981a). N. diversicolor is intermediate to the other 2 species, both in regulatory ability and sediment preference (Kristensen, 1981a).

Acknowledgements. My gratitude is due to Dr. J. P. Lomholt, Dr. F. C. Dobbs, Dr. L. M. Cammen and Professor K. Johansen for critical reading and valuable help in the preparation of my English manuscript. This research was supported by Grant no. 1979-22/523-42 from the University of Aarhus, Denmark.

\section{LITERATURE CITED}

Aller, R. C., Yingst, J. Y. (1978). Biogeochemistry of tubedwellings: a study of the sedentary polychaete Amphitrite ornata (Leidy). J. mar. Res. 36: 201-254

Bayne, B. L. (1967). The respiratory response of Mytilus perna L. (Mollusca: Lamellibranchia) to reduced environmental oxygen. Physiol. Zool. 40: 307-313

Bayne, B. L. (1971). Ventilation, the heart beat and oxygen uptake by Mytilus edulis $\mathrm{L}$. in declining oxygen tension. Comp. Biochem. Physiol. 40 A: 1065-1085

Beadle, L. C. (1961). Adaptations of some aquatic animals to low oxygen levels and to anaerobic conditions. Symp. Soc. Exp. Biol. 15: 120-131

Beis, I., Manousis, A., Barret, J. (1980). Studies on the respiration of the polychaete Ophelia bicornis. Comp. Biochem. Physiol. 67 A: 303-305

Bradford, S. M., Taylor, A. C. (1982). The respiration of Cancer pagurus under normoxic and hypoxic conditions. J. exp. Biol. $97: 273-288$

Cammen, L. M. (1980). The significance of microbial carbon in the nutrition of the deposit feeding polychaete Nereis succinea. Mar. Biol. 61: 9-20

Dales, R. P. (1961). Oxygen uptake and irrigation of the burrow by three terebellid polychaetes: Eupolymnia, Thelepus and Neoamphitrite. Physiol. Zool. 34: 306-311

Dales, R. P., Mangum, C. P., Tichy, J. C. (1970). Effects of changes in oxygen and carbon dioxide concentration on ventilation rhythms in onuphid polychaetes. J. mar. biol. Ass. U. K. 50: 365-380

Dales, R. P., Warren, L. M. (1980). Survival of hypoxic conditions by the polychaete Cirriformia tentaculata. J. mar. biol. Ass. U.K. 60: 509-516

Dam, L. van (1937). Über die Atembewegungen und das Atemvolumen von Phryganea-Larven, Arenicola marina, und Nereis virens, sowie über die Sauerstoffausnutzung bei Anodonta cygnea, Arenicola marina, und Nereis virens. Zool. Anz. 118: 122-128

Halcrow, K., Boyd, C. M. (1967). The oxygen consumption and swimming activity of the amphipod Gammarus oceanicus at different temperatures. Comp. Biochem. Physiol. 23: 233-242

Hamwi, A., Haskin, H. H. (1969). Oxygen consumption and pumping rates in the hard clam Mercenaria mercenaria: a direct method. Science, N.Y. 163: 823-824

Hyman, L. H. (1932). Relation of oxygen tension to oxygen consumption in Nereis virens. J, exp. Biol. 61: 209-221

Jørgensen, N. O. G., Kristensen, E. (1980). Uptake of amino acids by three species of Nereis (Annelida: Polychaeta). II. Effects of anaerobiosis. Mar. Ecol. Prog. Ser. 3: 341-346

Kristensen, E. (1981a). Økologiske studier over tre Nereisarter i Kysing Fjord og Vellerup Vig. M.S. thesis, University of Aarhus, Aarhus

Kristensen, E. (1981b). Direct measurement of ventilation and oxygen uptake in three species of tubicolous polychaetes (Nereis spp.). J. Comp. Physiol. 145: 45-50

Lindroth, A. (1938). Studien über die respiratorischen Mechanismen von Nereis virens Sars. Zool. Bidr. Uppsala 17 : $367-497$

Mangum, C. (1970). Respiratory physiology in annelids. Am. Sci. 58: 641-647

Mangum, C. P., Burnett, L. E. (1975). The extraction of oxygen by estuarine invertebrates. In: Vernberg, F. J. (ed.) Physiological ecology of estuarine organisms. University of South Carolina Press, Columbia, S.C., p. 147-163

Mangum, C. P., Saintsing, D. G., Johnson, J. M. (1980). The 
site of ion transport in an estuarine annelid. Mar. Biol. Lett. 1: 197-204

Mangum, C. P., Sassaman, C. (1969). Temperature sensitivity of active and resting metabolism in a polychaetous annelid. Comp. Biochem. Physiol. 30: 111-116

Mangum, C. P., Van Winkle, W. (1973). Responses of aquatic invertebrates to declining oxygen conditions. Am. Zool. 13: $529-541$

May, D. R. (1972). The effects of oxygen concentration and anoxia on respiration of Abarenicola pacifica and Lumbrineris zonata (Polychaeta). Biol. Bull. mar. biol. Lab., Woods Hole 142: 71-83

Muus, B. J. (1967). The fauna of danish estuaries and lagoons. Distribution and ecology of dominating species in the shallow reaches of the mesohaline zone. Meddr Danm. Fisk.-og Havunders. ny ser. 5: 3-316

Newell, R. C., Kofoed, L. H. (1977). The energetics of suspension feeding in the gastropod Crepidula fornicata $\mathrm{L}$. J. mar. biol. Ass. U.K. 51: 161-180

Newell, R. C., Northcroft, H. R. (1967). A re-interpretation of the effect of temperature on the metabolism of certain marine invertebrates. J. Zool., Lond. 151: 277-298

Petersen, J. A., Johansen, K. (1967). Aspects of oxygen uptake in Mesochaetopterus taylori, a tube-dwelling polychaete. Biol. Bull. mar. biol. Lab., Woods Hole 133: 600-605

Prosser, C. L. (1973). Comparative animal physiology, Vol. I. W. B. Saunders Company, Philadelphia, London, Toronto

Rasmussen, E. (1973). Systematics and ecology of the Isefjord marine fauna (Denmark). Ophelia 11: 1-507

Revsbech, N. P., Sørensen, J., Blackburn, T. H. (1980), Distribution of oxygen in marine sediments measured with microelectrodes. Limnol. Oceanogr. 25: 403-411
Schöttles, U. (1978). Investigations of the anaerobic metabolism of the polychaete worm Nereis diversicolor $M$. J. Comp. Physiol. 125: 185-189

Schöttler, U. (1979). On the anaerobic metabolism of three species of Nereis (Annelida). Mar. Ecol. Prog. Ser. 1: 249-254

Scott, D. M. (1976). Circadian rhythm of anaerobiosis in a polychaete annelid. Nature, Lond. 262: 811-813

Scott, D. M., Mazurkiewicz, M., Leeman, P. (1976). The longterm monitoring of ventilation rhythms of the polychaetous annelid Nereis virens Sars. Comp. Biochem. Physiol. 53 A: $65-68$

Shumway, S. E. (1979). The effects of body size, oxygen tension and mode of life on the oxygen uptake rates of polychaetes. Comp. Biochem. Physiol. 64 A: 273-278

Theede, H. (1973). Comparative studies on the influence of oxygen deficiency and hydrogen sulphide on marine bottom invertebrates. Neth. J. Sea Res. 7: 244-252

Theede, H., Schaudinn, J., Saffé, F. (1973). Ecophysiological studies on four Nereis species of the Kiel Bay. Oikos 15 (Suppl.): 246-252

Thompson, R. J., Bayne, B. L. (1972). Active metabolism associated with feeding in the mussel Mytilus edulis L. J. exp. mar. Biol. Ecol. 9: 111-124

Weber, R. E. (1978). Respiratory pigments. In: Mill, P. J. (ed.) Physiology of annelids. Academic Press, London, New York, San Francisco, p. 393-446

Wells, G. P., Dales, R. P. (1951). Spontaneous activity patterns in animal behaviour: the irrigation of the burrow in the polychaetes Chaetopterus variopedatus Renier and Nereis diversicolor O. F. Müller. J. mar. biol. Ass. U.K. 29 : $661-680$ 